\title{
The Research of Bracket Culture in Chinese Traditional Wooden Architechture
}

\author{
Tang Xiya \&Zhong Chen \\ Department of architechture, Hunan University of Technology, Zhuzhou, Hunan , 412007
}

\begin{abstract}
KEYWORD:Traditional; Wooden structure; Architechture;Bracket;Culture
ABSTRACT:Bracket has experienced vicissitudes for hundreds of years in Chinese traditional wooden architechture, so that the natural color on its surface had long been faded, however, the marvelous sculptures on it has always been suggesting that the lives of the ancients and it is the fantastic designs, exquisite carving skills, vivid patterns and lifelike interests that have shown us the artistic charm of Chinese traditional wooden architechture. In order to arise the enthusiasm about bracket,this passage intends to disuss the implication and spirit culture of the bracket by analyzing the historical evolution, sculpt, size and materials such characteristics.
\end{abstract}

\section{WITH REFERENCE TO THE BRACKET}

Bracket also named as "ChengGong", "XieCheng", "TuoZuo", which is a diagonal wooden stick out of the eave column, and the crossbar is a purlin which is used for bracing the cornice. Bracket can not only increase the roof eaves to shelter from the wind and rain,but also transmit the upper gravity to the eave column in order to maintain the stability of the buildings.( Figure 1) Initially, the bracket was not be accepted by publicity for its heavy body, so it is difficult to see it in early traditional wooden architechture. Thanks to the development of traditional woodcarving techniques, bracket had been prevailed in traditional wooden architectures. Bracket, gradually became a significant component with the arrival of woodcarving techiniques in Ming and Qing Dynasties. So in Ming and Qing Dynasties, brackets could be found everywhere in traditional wooden architecture, which were mainly concentrat-ed in the ancestral hall, luxury, Academy, temples, shops, offices and other buildings with high standards of construction. Bracket culture is the essence of the implication of the Chinese traditional architectural culture with fleshy or light shapes and fantastic carving skill.

\section{THE HISTORICAL EVOLUTION OF BRACKE- T IN TRADITIONAL WOODEN ARCHITECTUR-E}

The history of bracket was shorter than other timber structural members and there was not any evidence proved that brackets appeared before Ming Dynasty. The "early" bracket was a diagonal wooden stick, just like the bottle spout, and no decoration on it. In early Ming Dynasty, extremely simple lined carving was appeared the bracket . In the midterm of Ming Dynasty, the decoration of "bracket" had been valued, much intagliated decorative lines were used to carve, then the volume grass carving were appcared. Due to the prosperity of the economy and increases of the artists, the bracket and wood were combined perfectly, the clumsy image of bracket had become flexible for the wood carving technology, hence the bracket was popular among the people.

\section{FEATURES OF THE BRACKET IN TRADI-TIONAL WOODEN ARCHITECTURE}

In the early Ming Dynasty "bracket" was only a thin or wooden stick which was mainly to support and brace the cornice with slighted decorations such as some bamboo, flowers and birds, nut pines and other simple patterns; in the midterm of Ming Dynasty, "bracket" began to into the shape of a dragon which was upside down and the linear feature of dragon is apparent, mellow and smooth, while the pattern trend is still simple; Bracket in Qing Dynasty was oblique wood which the upper part was bigger than lower, during this time, the modeling and patterns was not limited by perspective principle on account of the use of the technics of bracket was managed by adopting 
the cavalier perspective and bird's-eye perspective in Chinese traditional painting for composition, so the decoration styles were quite abundant. In the early period of the Republic of China, owing to the impact of the western architectural style, the form of Chinese architecture began to "Westernization", the traditional architecture of "bracket" gradually withdraw from the stage of history of Chinese architecture.

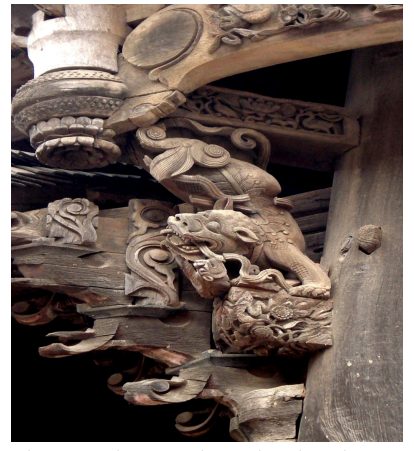

Figure1:The round carving bracket of "Shichu Mingmen"in dwelling,Nanwu

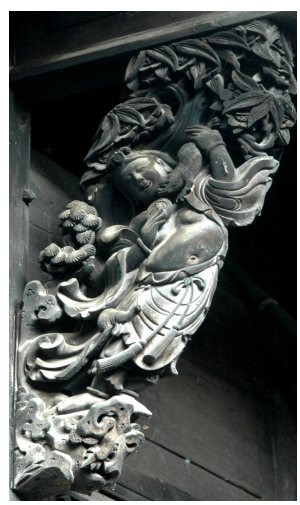

Figure 3:The round carving of DeChunTang pharmacy(Qing)

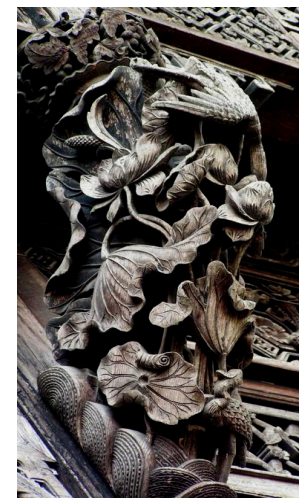

Figure4:The round carving bracket of Hweichow lotus(Qing)

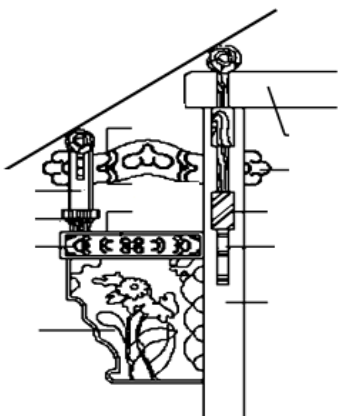

Figure2: The structure of bracket

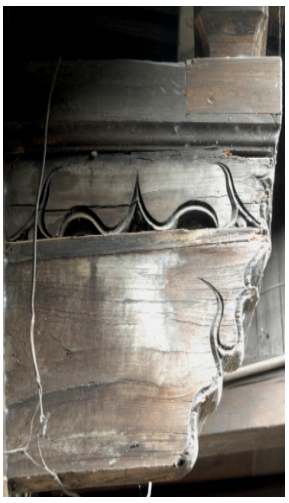

Figure5: Line mark bracket in

Xiao YouTang(Ming)

\section{THE VOLUME CHARACTERISTICS OF BRAC- KET IN TRADITIONAL WOODEN ARCHITECT-URE}

In traditional wooden structure, mostly the width of the bracket is $450-600 \mathrm{~mm}$, the thickness is $150-250 \mathrm{~mm}$ and mostly the height is about $600 \mathrm{~mm}$, as some large bracket, the height of some huge bracket is more than $1000 \mathrm{~mm}$. The thickness of the traditional bracket bars is wider than the thickness of the bracket and its length depending on the position above the support member and the height of the section is about $150 \mathrm{~mm}$. Some brackets take two bars and supported with lotus leaves pier, some other brackets have unconspicuous bars. The bracket under the melon column is about $120 * 120 \mathrm{~mm}$. The bracket and the other components of the mortise are combined with tenon connection, which have constituted a complete stress system and modeling system.

\section{THE MATERIAL CHARACTERISTICS IN TRA-DITIONAL WOODEN ARCHITECTURE}

The selection of the wood which is used to make bracket is very strict, and the high strength, fine microstructure, nice texture and good durability, with wide tree diameter and indeformable wood are required. Therefore, camphor, cypress and ash as the ordinary material to make bracket, and the luxurious houses adopted ginkgo, Phoebe, rosewood, red sandalwood as materials, while the low standard constructions used local materials, such as Chinese fir or other miscellaneous. When carving the bracket, carpenters analyze advantages and disadvantages of materials, developing its ments and avoiding its defects, hollow out techinics are handled on wood which the pith is soft, and transformed the knots and holes into the elements of composition or inlaied other wood to carve. Making the most of material achieve more natural perfect shape. 


\section{THE ART FEATURE OF THE BRACKET IN TRADITIONAL WOODEN ARCHITECTURE}

The artistic style of bracket in Ming and Qing Dynasty were different: The modeling of bracket in Ming Dynasty were long streamlined, whichis mellow and terse, the slyle of carving tends to rough. While In midterm of Qing Dynasty, because of the prevalence of close windtight architectural trends, the style of bracket had become structured, rigorous, much more linears, were used the upper part of it was wide and the other was narrow, what's more,the contents of carving is more complicated. During the period of the Republic of China, the bracket was influenced by the perspective of the realistic and reasonable proportion of philosophy in Western sculpture art, hence the bracket began to westernize and gradually became vestigial. The subtlety of bracket in traditional wooden architecture is not the standard and efficacy of itself, but the decorative art attach to it and the deep cultural meaning in it.

\section{Carving craft of bracket}

The carving craft of bracket is limited to simple lines in early Ming Dynasty, including the relievo and intagliated carving; in the middle of Qing Dynasty, the golden age of the development of carving technology, line engraving, shallow relief, high relief, double-sided carving, carving deep hollow, openwork carving, three round carving, half round carving, cylindrical carving and Pindou carving were used on it. In the late Qing Dynasty, the carving of laid emphasison composition of the full picture of the master-slave relationship, so the main position of bracket adopted hollow carving and round carving, other parts used rilievo and line engraving, The carving of bracket combined with rigid and soft. Various of carving process is often used crossly to the complex bracket for showing up the texture and exquisite carving of wood, so most of the bracket in late Qing Dynasty are extremely beautiful because of the process of extraordinary skilled artisans.

\section{Decorative themes of the bracket}

There are some brackets with same or different decorations in traditional wooden buildings, but the brac-kets with different decorations still express the same subject. The theme of Traditional bracket mostly were historical stories, folk legends, mythsor opera stories with educa-

tional meaning. Some other carving themes were different and special showing satisfactions and describingfavorites. In a word, the carved content of brackets mostly are four parts figures, landscap es, animals, birds and flowers and each other can be freely assembled.

\section{Theme of animals}

The theme of animals are lions, deer, elephants, horses, dragons and tigers. With homophonic toreflect the moral, for instance, the elephants means "renewal", "good luck" and "spectacular"; sika deer is a symbol of longevity, "deer" in Chinese is homophonicand with "Lu", representing wealth and fortune; the lion means "safety", (Figure 2) "tought by famous master "," be an official to TaiShi ",among the people, lion also stand for avoiding against evil and protecting the house.And the horses sheep, tigers, dogs, cattle not only mean faith and obedience infeudality, "achieve immediatevictory "and" three rams bringing bliss", "like tiger" and other auspicious significance; in addition, chicken, duck, goose, pig, ox, sheep represent prosperous.

\section{Theme of figures}

The theme of figures in bracket is extensive, it is also the essence of the decorations of bracket. The theme effigures among the people are"Fukurokuju","The HarmoniousImmortalsBring Marri-ed Happiness", " Liu Hai Playing with Golden Toads" and "Carp jump longmen", "The Eight Immortals Crossing the Sea", "fishing, woodcutting, farming and reading ", "Kuixing Diandou". The historical allusions opera figures, folk myths and literati image such as "lyre playing, chess, calligraphy and painting","plum, orchid, bamboo and chrysanthemum"," first on the list for 
the three degrees in succes sion","Guo Ziyi's birthday party", "Wen Gong JingZhen", "win the number one scholar" are also the subjects of figural carving in bracket. Each characters is elegant, with form and spirit.(Figure 3)

\section{Theme of paints and objects}

In most cases, themes of plants and objects were the auxiliary patterns in bracket carvings, but there were alse some special examples regardless of the position in public sculpture composition, most of the modeling processing in plants and objects are stylized. Peach, pines, rocks are symbols of longevity, lotus seeds, pomegranate with many children and grandchildren, clouds, waves represent noble and plum, orchid, bamboo, chrysanthemum, pine, cypress, lotus (Figure 4) are compared to noble sentiments. Buddhist treasures, white, lotus, flame convey the Buddhist faith while compass, mirror, peach wood sword, Mount Tai stone reflect the concept of Fengshui.

\section{Geometric patterns}

Geometric patterns had always been a decorative theme from ancient to modern times, there were also many geometric patterns in bracket,which were used to express the householder's persuit of good fortune, such as fret, wind pattern, Fang Sheng grain, fylfot pattern to represent many generations, as well as the cross, five star, four pictographs, Chinese zodiac patterns and so on which represented the primitive worship.(Figure 5)

\section{CONCLUSION}

Chnese traditional wooden architecture of the bracket experenced hundreds of years of hard life, the surface of the original pure wood color already dimming. But its surface wonderful exquisite carvin $\mathrm{g}$ art, through the space and time, constantly expresses lives and fantastic designs of the ancients. $\mathrm{T}$ he art charm of traditional wooden architecture is fully embodied by its ingenious mind, elaborate $\mathrm{c}$ arving, vivid images and charm. Brackets, the most shining pearl of Traditional wooden architecture , not only endow life to the art of building but also expand the implication of the traditional woode $\mathrm{n}$ architecture and enrich the spiritual and cultural meanings of the traditional archit-

Ecture.

The National Department of Education Planning Fundation Project: Dongyang Traditional ooden Structure Building Components' Decorative Art System and Description Mechanism.

\section{Research}

Project Number: 14YJA760030 About the author: Tang Xiya(1972-), female, Zhuzhou, Hunan, master of Engineering, Associate Professor. The main research directions: traditional building culture research.

\section{References:}

[1] Wang Zhongfen, The Folk Houses in Dongyang, Zhejiang(M). Tianjin Publishing Company, 2008.01

[2] Liucheng, "The habitats of emotions" _ About the Decoration Culture Signs in Chinese Traditional Architecture(J), Art and Design, 2014.06 